\title{
Tonal synchrony in mother-infant interaction based on harmonic and pentatonic series
}

\author{
Martine Van Puyvelde ${ }^{\mathrm{a}, *}$, Pol Vanfleteren ${ }^{\mathrm{a}, \mathrm{b}}$, Gerrit Loots ${ }^{\mathrm{a}, \mathrm{c}}$, Sara Deschuyffeleer ${ }^{\mathrm{a}}$, \\ Bart Vinck $^{\mathrm{d}}$, Wolfgang Jacquet ${ }^{\mathrm{a}}$, Werner Verhelst ${ }^{\mathrm{a}}$ \\ ${ }^{a}$ Vrije Universiteit Brussel (VUB), Pleinlaan 2, B-1050 Brussels, Belgium \\ ${ }^{\mathrm{b}}$ Universiteit van Amsterdam (UvA), Netherlands \\ c University of Ghent (UG), Belgium

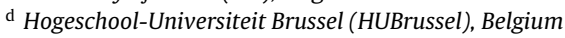

\section{A R T I C L E I N F O}

\section{Article history:}

Received 8 May 2009

Received in revised form

15 December 2009

Accepted 9 April 2010

\section{Keywords:}

Mother-infant interaction

Vocal interaction

Tonal synchrony

Harmonic series

Pentatonic series

Infant-directed speech

\begin{abstract}
A B S T R A C T
This study reports the occurrence of 'tonal synchrony' as a new dimension of early mother-infant interaction synchrony. The findings are based on a tonal and temporal analysis of vocal interactions between 15 mothers and their 3-month-old infants during 5 min of free-play in a laboratory setting. In total, 558 vocal exchanges were identified and analysed, of which $84 \%$ reflected harmonic or pentatonic series. Another $10 \%$ of the exchanges contained absolute and/or relative pitch and/or interval imitations. The total durations of dyads being in tonal synchrony were normally distributed $(M=3.71, \mathrm{SD}=2.44)$. Vocalisations based on harmonic series appeared organised around the major triad, containing significantly more simple frequency ratios (octave, fifth and third) than complex ones (non-major triad tones). Tonal synchrony and its characteristics are discussed in relation to infant-directed speech, communicative musicality, pre-reflective communication and its impact on the quality of early mother-infant interaction and child's development.
\end{abstract}

(c) 2010 Elsevier Inc. All rights reserved.

Interaction synchrony between mothers and infants during the first months of life is generally accepted as a core feature of the quality of early mother-infant interaction and as a foundation for the later socio-emotional and cognitive development, as well as for the language acquisition of the child. Interaction synchrony - broadly defined as the temporal coordination of behaviors, affective states, and biological rhythms between mother and child - has been investigated extensively as: (a) a match or co-occurrence between the behaviors or affective states of mother and child, (b) the sequential relations between the behavior of one partner and the following behavior of the other, and (c) the ongoing lagged associations between the mother's and infant's stream of behaviors (see Feldman, 2007, for a review of early interaction synchrony).

In addition to gaze, affect, proximity, affectionate touch and physical contact, mothers' speech has been recognized as a powerful tool to create interaction synchrony (Gratier, 2000, 2003; Jaffe, Beebe, Feldstein, Crown, \& Jasnow, 2001; Malloch, 1999/2000; Miall \& Dissanayake, 2002; Papousek, 1992; Schögler, 1998; Stern, 2002). Many studies have shown that infantdirected (ID) speech is characterized by specific features that differentiate it from adult-directed (AD) speech. Mothers raise their pitch, enlarge their pitch range, use highly exaggerated pitch contours, create more rhythm, slow down their tempo, repeat sounds and elongate their vowels when speaking to their infants (Fernald, 1992, 1993; Fernald \& Simon, 1984; Fernald et al., 1989; Gratier, 2003; Grieser \& Kuhl, 1988; Papousek, 1992; Stern, 2002; Stern, Spieker, \& MacKain, 1982).

\footnotetext{
* Corresponding author. Tel.: +32 495239543.

E-mail address: mvpuyvel@vub.ac.be (M. Van Puyvelde).
} 


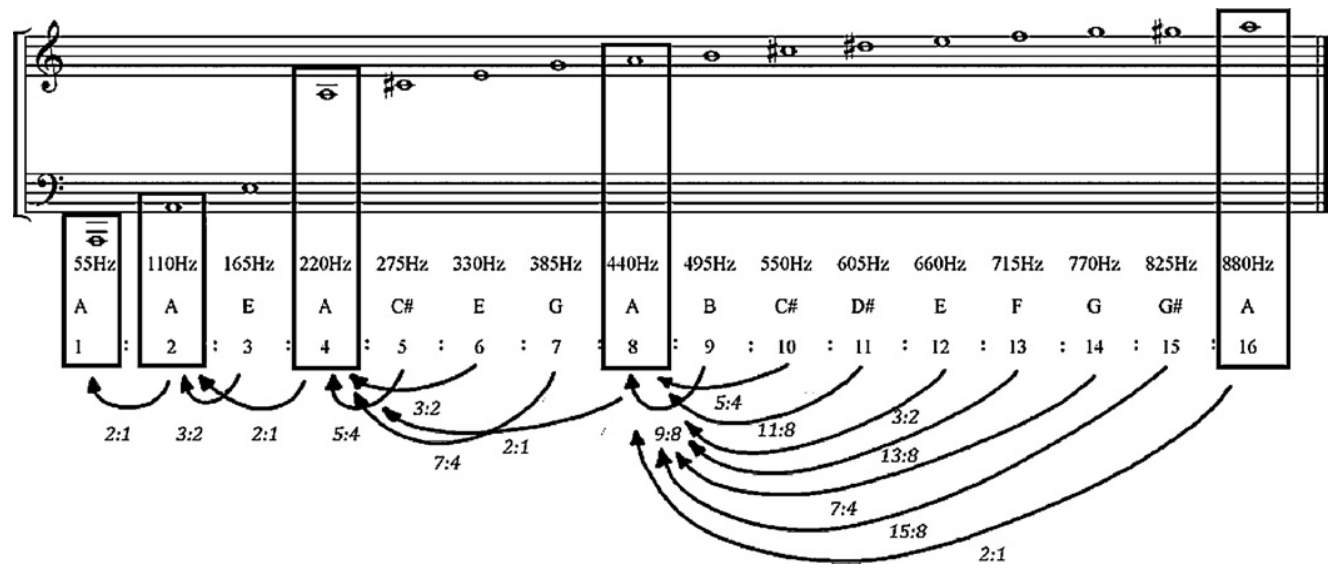

Fig. 1. Harmonic series built on A. Under the notes are mentioned the frequency (Hz), the note-name and the harmonic number. Harmonic number 1 is the fundamental frequency or first harmonic, harmonic number 2 is the second harmonic and so forth. The frequency of every tone is a multiple of the fundamental frequency. These relations are expressed in ratios. For example, harmonic number 3 is related to harmonic number 2 (octaviation of the fundamental frequency) with the ratio 3:2. This study considers the harmonics in relation to the fundamental frequency and its octaviations: what we call the 'tonal centre'. The tones of the tonal centre are indicated by the rectangles. For example, harmonic number 6 is related to the fourth harmonic (ratio $6: 4=$ ratio $3: 2$ ) and not to the fifth harmonic.

Several functions have been ascribed to the specific features of ID speech. Some authors emphasize that ID speech is: (a) functional to obtain or maintain the attention of infants (Cooper \& Aslin, 1990; Fernald \& Simon, 1984; Papousek, 1996a; Werker, Pegg, \& McLeod, 1994), (b) to communicate affective information to the infant (Trainor, Caren, Austin, \& Desjardins, 2000), and (c) to aid language learning and communication skills acquisition (Jaffe et al., 2001; Papousek, 1992; Stern, 2002). Trainor et al. (2000) used the five acoustic features that define the ID speech style (pitch, pitch contour, pitch range, tempo, and rhythmic contour) to compare samples of ID speech with those of emotional AD speech. They found only a few acoustic differences between the two. In comparison to the more inhibited expression of emotion in typical adult interactions, what was peculiar to ID speech was the widespread expression of emotion.

Other scholars emphasized the musical qualities of ID speech and pointed to the musical nature of mother-infant communication (Fernald, 1985, 1989; Papousek, 1996b; Trevarthen, 1999/2000). According to Malloch and Trevarthen (2008), early common musicality creates companionship. It encourages sharing coordinated embodied space and time and facilitates and energizes meaning in communication. Malloch (1999/2000) used music as a model to examine the vocalisations of a mother-infant dyad acoustically. In addition to temporal interaction sequences, he described matches in pitch between mother and infant and variations in timbre in the mother's speech. In other studies, the preverbal communication between mother and infant has been compared to a jazz improvisation (Gratier, 2000; Schögler, 1998) because of the rhythmic improvised character of the coordinated interactive narratives (Schögler, 1998). Bergeson and Trehub (2007) suggested that mothers have their own signature in their way of talking to their infant, but questioned the appearance of a real musical structure.

In the present study we report an analysis of the vocal interactions between mother and infant based on the phenomenon of harmonics. We suggest that these early mother-infant interactions are characterized by the joint construction of harmonic and pentatonic series as well as imitations of these harmonics.

Before continuing, we would like to mention that, like Eckerdal and Merker (2008), we approach labelling sequences of pitches as 'music' with caution. The authors described music as a recognizable pattern of pitch and rhythm to which one can return. We think it is important to underline that the element of cultural influence cannot be eliminated when speaking of music. Therefore, in this study, we do not speak of 'music', but prefer to use the word 'tonality'. Cross-culturally, music has one common nature-related aspect: namely, sound. And almost every sound in our environment is a multi-tone complex consisting of a number of simultaneous pure tones called harmonics, nature tones or overtones. As we will explain in more detail below, together with the pentatonic series - a five-tone series system that is deduced from the harmonic series harmonics can be considered universal tonal aspects. The human voice also produces tones rich in harmonics. Already in the womb, an infant is surrounded by these natural ratios of the harmonic series produced by its mother's voice. A foetus is able to identify the maternal voice (Kisilevsky et al., 2003, 2009) that is internally transmitted via body tissues and bones (Lecanuet, 1996). An unpublished work of Petitjean (1989 in Lecanuet, 1996) revealed that human bone structure appears to be an excellent conductor of harmonics through the spine and pelvic arch.

The sound of a human voice and most of the musical instruments we know consist primarily of simple harmonic series, but can also contain complex inharmonic series. The vibrations of a simple harmonic series can be defined as a tone. A complex inharmonic sound is not perceived as a tone, but as is the case with a snare drum, as a noise or indefinable sound. In this study we will consider the concept of simple harmonic series and refer to them from now on as 'harmonics'. Fig. 1 shows the hierarchic structure of a harmonic series. When a string - as an analogy to the vocal cord - is brought to sound, 
Table 1

Overview of the intervals and the differences in cents between equal-tempered system and just intonation (Burns \& Dixon, 1982).

\begin{tabular}{lccc}
\hline Name & Cents in equal-tempered system & Cents in just intonation & Difference \\
\hline Unison & 0 & 0 & 0 \\
Minor second & 100 & 111.7 & +11.7 \\
Major second & 200 & 203.9 & +3.9 \\
Minor third & 300 & 315.6 & +15.6 \\
Major third & 400 & 386.3 & -13.7 \\
Perfect fourth & 500 & 498.1 & -1.9 \\
Tritone & 600 & 590.2 & -9.8 \\
Perfect fifth & 700 & 702 & +2 \\
Minor sixth & 800 & 813.7 & +13.7 \\
Major sixth & 900 & 968.4 & -15.6 \\
Minor seventh & 1000 & 1088.3 & -31.2 \\
Major seventh & 1100 & 1200 & -11.7 \\
Octave & 1200 & & 0 \\
\hline
\end{tabular}

we perceive the lowest fundamental frequency (first harmonic or harmonic number 1) as the most salient component. But a few softer sounding harmonics will resonate together with this fundamental frequency (harmonic numbers 2-16 in Fig. 1). These harmonics blend or harmonize with the fundamental frequency and give the impression of a single tone (Sadie, part 8, p. 165). The relative strength of each harmonic generates the quality, or colour, to the tone heard.

As a result of the natural distribution of the energy through the vibrating string, the string will not only vibrate as a whole, but also as two halves, three parts, four parts and so forth (Sadie, 1980). Therefore, the frequency of every harmonic in a harmonic series is a multiple of the lowest fundamental frequency (see Fig. 1: 55-110-165 Hz and so forth). Doublings of a frequency (musical term: octaviation) are perceived as being similar (Burns \& Dixon, 1982; Dowling \& Harwood, 1986) even by infants (Demany \& Armand, 1984). Therefore harmonic numbers 2, 4, 8 and 16 are all octaviations of the fundamental frequency (harmonic number 1) and obtain the same note-name. In this study we exclusively consider the other harmonics in relation to this fundamental frequency and its octaviations. From now on we will designate the fundamental frequency and its octaviations as the 'tonal centre' (for more explanation, see Fig. 1).

The ratios, as obtained in Fig. 1, deviate slightly from the ratios between intervals that are used in an equal-tempered system. In equal temperament an interval - usually the octave - is divided into a series of equal frequency ratios. In our Western music system, the common tuning system is twelve-tone equal temperament which divides the octave into 12 . This equal-tempered system can be measured in cents, which divide the octave into 1200 cents. So, in a twelve-tone equal temperament, which divides the octave into 12 equal parts, one semitone corresponds to 100 cents. As a result of this recalculation, the frequency, and thus, also the ratio, between two tones, differs from the just intonation of the natural ratios (see Table 1: Burns \& Dixon, 1982). The difference between the exact value in a twelve equal-tempered system and the just intonation in cents of a harmonic never exceeds 50 cents. So, in agreement with the common frequency-analysis programs, we accepted a deviation up to 50 cents above or under a note for assigning a note-name to a harmonic.

It was already Pythagoras who suggested that the simpler the frequency ratio between two tones, the more consonant (i.e., a pleasant and stable sound sensation produced by 2 tones) they will be perceived (Burns \& Dixon, 1982). The octave (2:1) and fifth (3:2) are the only intervals that have maintained their status of perfect consonance throughout the history of Western music (Sadie, 1980, part 6, p. 543). The octave, as it forms the boundary for scales cross-culturally, has been labeled as the 'focal point' in cross-cultural music (Meyer, 1956, pp. 63, 231). The octave (harmonic numbers 1, 2, 4, 8, 16), the fifth (harmonic numbers $3,6,12$ ) and the third (harmonic number 5,10$)$ correspond to the tones of the Western major triad that grants its consonant character to its simple frequency ratios $(2: 1 ; 3: 2 ; 5: 4)$. Research supports that infants (Schellenberg \& Trehub, 1994; Zentner \& Kagan, 1998) as well as adults (Blood, Zatorre, Bermudez, \& Evans, 1999; Koelsch, Fritz, von Cramon, Müller, \& Friederici, 2006) prefer music based on simple frequency ratios and suggests that this preference might be biologically prepared (Papousek, 1996a, 1996b; Schellenberg \& Trehub, 1994, 1996a; Trehub, 2001; Zentner \& Kagan, 1998). People appear to have a particular predisposition to process simple frequency ratios in a different way than complex frequency ratios. There may therefore be, as is the case with birds (Marler, 1990), innate learning preferences. Simple frequency ratios settle more easily as a stable perceptual representation in our minds than complex frequency ratios (Schellenberg \& Trehub, 1994). Children and adults without any musical education (Schellenberg \& Trehub, 1996a), as well as infants (Schellenberg \& Trehub, 1996b), can more easily detect changes in intervals related to simple frequency ratios compared to complex frequency ratios. Helmholtz (1863) was the first to give a plausible, but not necessarily unique, explanation for the phenomenon of consonance and dissonance between two tones in the unique behavior of their harmonics. The simpler the ratio between the fundamental frequency of two tones, the more harmonics they have in common. For example, two tones an octave apart share all their harmonics, while in the interval of a tritone (the most complex frequency ratio 11:8), for example, no identical harmonics are shared (Narmour \& Solie, 1988, pp. 142-150).

Some musical systems bridge over the octave by five tones and are therefore called pentatonic series. For this study we want to mention one pentatonic series - the anhemitonic pentatonic - so called, because it is built out of ascending fifths, or simple frequency ratios 3:2. Starting from the fundamental frequency, this fifth upward is made four times. When we place these five tones inside the octave, we obtain a scale without semitones (ratio 16:15) (see Fig. 2) that is perceived as 

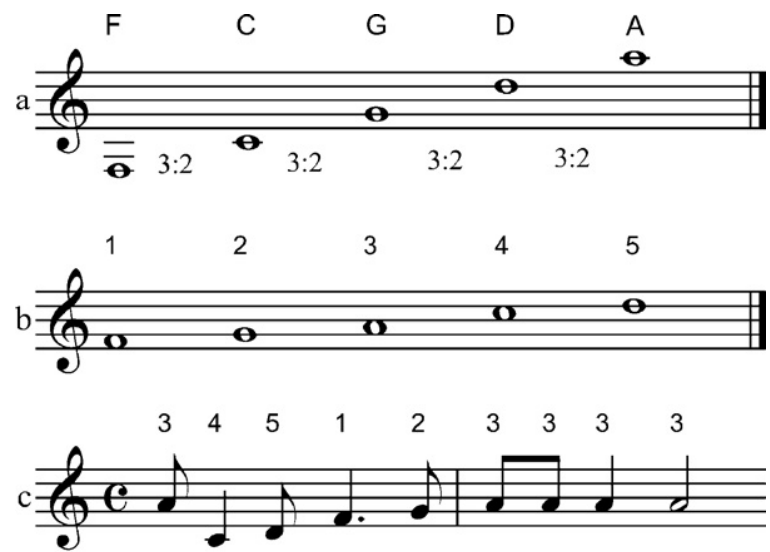

No - bo - dy knows the trou-ble I've seen...

Fig. 2. (a) Ascending fifths or simple frequency ratios 3:2 starting from an F (F-C-G-D-A). Together they form the tones of a pentatonic series. (b) The five notes of bar (a), placed within an octave, form the F-pentatonic scale ( $F=$ number $1 ; G=$ number $2 ; A=$ number $3 ; C=$ number 4 ; $D=$ number 5 ). (c) Nobody knows (Negro-spiritual based on the F-pentatonic scale). The numbers above the notes refer to the notes of the pentatonic series in bar (b).

extremely consonant and relaxing. It is therefore used as a basis for many children's songs. We consider the anhemitonic pentatonic scale as a cultural deduction of a universal tonal aspect. Since 2000 BC (Kennedy, 1994, p. 485), pentatonic music systems have occurred cross-culturally throughout the five continents (Sadie, 1980, part 14, p. 353) (see Fig. 2).

Besides the clear link with the harmonic series there is an important differentiating aspect between both. The tone of the third fifth starting from the fundamental frequency (D or tone 5 in Fig. 2) makes up the major sixth in relation to the fundamental frequency. This major sixth in relation to the fundamental frequency does not occur in the harmonic series. The pentatonic scale thus has four communal and one unique tone in comparison to the harmonic series.

\section{Method}

\subsection{Participants}

This study is part of a larger longitudinal research project on mother-infant interaction during the first 2 years of life. Twenty-nine mothers were recruited during childbirth information sessions for pregnant women at two different academic hospitals (Universitair Ziekenhuis Brussel and Imeldaziekenhuis Bonheiden). Interested candidates were contacted after childbirth and asked if they still agreed to participate in the study. After signing an informed consent, mothers were invited to the observation laboratory of the Vrije Universiteit Brussel for audio and video recordings of free-play sessions when their infants were 3, 6, 9, 12 and 18 months old. The recordings took place when the infant was in an awake and alert state. For the current study, we randomly selected the recordings of 15 mother-infant pairs that were taken when the infants were 3 months old. All infants were healthy, first-born children. They were full-term born and had a 1-min Apgar score of 7 or more. At the time of the first recordings, all 15 mothers were between 25 and 33 years old. Their mean age was 28 years and 1 month ( $\mathrm{SD}=4.5$ years). All mothers were native Dutch speakers. Except for one, all of them received at least 3 years of higher education. The mean number of total years of education was 15 years 6 months ( $S D=2.8$ years).

\subsection{Apparatus}

For the audio and video recordings of the mother-infant play sessions, a specific observation laboratory was designed at the Vrije Universiteit Brussel (Jiang et al., 2007). Four pan-tilt-zoom dome cameras (Panasonic WV-CS950) and two clip-on directional microphones (Shure Microflex MX184) were used. The PC displayed a 4-way split-frame. The audio-analyses were made by two professional musicians with the help of two frequency-analysis programs, Cool Edit Pro version 2.1 (Syntrillium Softwares) and Melodyne version 3.2.1.5 (Celemony Softwares GmbH).

\subsection{Procedure}

Observation sessions at the laboratory were scheduled no longer than 10 days after the infants became 3 months old. A session consisted of a semi-structured interview about pregnancy and the first 3 months of motherhood, a Bayley Scales of Infant Development, Dutch version (BSID-II-NL; van der Meulen, Ruiter, lutje Spelberg, \& Smrkovsky, 2000), and at 12 and 18 months also a Mc Arthurs' Communicative Development Inventories, Dutch version (N-CDI; Zink \& Lejaegere, 2002). After testing, mother and infant were observed in free-play sessions in another part of the room. For the recordings at 3 months, the mother sat on a chair and the infant was placed in an infant seat on a table. Play sessions lasted 15 min: 5 min 
without a toy, 5 min with a standard toy (according to the age of the infant) and 5 min with a toy the mother had brought from home. For this study we only used the recordings of the condition without a toy. Every dyad got 1 min of interaction playtime before cameras started recording to give them time to habituate to the lab situation. During the play sessions the researcher sat in an adjoining room in order to follow the video and audio recordings. There were no interruptions except to give instructions for the next 5-min condition. After the play session mother and infant were invited to the control room to watch and comment on the recordings.

\subsection{Data analysis}

Every vocal sound of the infant (i.e., when the vocal cords vibrated, producing a definable sound that could be reliably translated to a pitch) was selected as meaningful for analysis. Sounds produced by the infant like breathing, coughing, sighing and clacking of the tongue that could not be translated into a pitch and did not require activity of the vocal cords were excluded from analysis. Some vegetative sounds that were not meant as vocalisation but to which a pitch could be easily attributed (as was often the case when the infant hiccupped) were included when the sound was followed by a response of the mother adapting her vocalisation to the pitch of the infant's involuntary sound.

The vocalisations of the infant were expanded by the preceding and/or succeeding vocalisations of the mother to define interaction moments of mutual vocalisations. For this we began by analysing the vocalisations of the mother before and after the selected utterances of the infant. In these mutual vocalisations we searched for a tonal context in terms of harmonics or pentatonic series. When we found a tonal context that preceded the utterance of the infant we analysed backwards and took the first tone of the tonal context as the onset of the interaction moment. When we found a tonal context that succeeded the utterance of the infant we analysed forwards until this tonal context ended. We took the last tone of the tonal context as the offset of the interaction moment. These 'Tonal Interaction Moments' (TIM) were temporally marked. It is worth mentioning that these TIMs did not always appear analogous to the grammatical structure of a sentence. In other words, the grammatical beginning or ending of a sentence did not automatically correspond with the onset or offset of a TIM.

A general speech pattern is relatively easy to transcribe into discrete notes because of the natural segmentation into syllables. However, ID speech and some utterances of the infants often demonstrate a continuous course (i.e., a sliding pitch pattern or fluctuation that we will label as 'glissando' 1 ) that lends itself less to segmentation in view of a reliable and discrete pitch transcription. Therefore it was necessary that professional musicians listened to these utterances in order to deal with less clear segmentations. Two musicians trained themselves with the help of two frequency-analysis programs, Cool Edit Pro and Melodyne, and reached an inter-rater reliability of 91.01 (Cohen's $\kappa)^{2}{ }^{2}$

By assigning note-names we make use of the equal-tempered paradigm tuned to a standard pitch of $440 \mathrm{~Hz}$ for an $\mathrm{A}$. This equal-tempered system does not correspond perfectly with the frequencies of a harmonic series. So when we want to include the harmonics in the equal-tempered system, an adjustment to the closest note-name is required. Just as with Cool Edit Pro, for assigning a note-name, we accepted a deviation up to 50 cents above or under a note. As such, it is important to mention that the difference between the exact value in a twelve equal-tempered system and the just intonation in cents of a harmonic never exceeds the norm of 50 cents (see Table 1). Strictly theoretically speaking, the A 440 standard should not be necessary in this study because we are looking for relations and ratios between pitches in terms of pentatonic scales and harmonics which implies a relative, and not an absolute, way of listening. Thus, in some cases, the relative distance between two notes perceived by ear did not correspond with the translation from pitch to note-names of the computer programs. For instance, when a frequency analyzer registers a very low G\# $(-48)$ followed by a very high $\mathrm{C \#}(+48)$, the program will note a fourth (G\#-C\#) instead of a fifth (G-D) that a musician would hear by ear. The interaction moments that showed this problem were all selected and presented to 12 professional musicians who were uninformed about the goal of the research. They could listen to the fragments as many times as they wanted and answered questions like: "Which distance do you hear: a second, third, fourth, fifth ..."; "Do you perceive the following tones as the same?"; "What kind of chord do you hear?". This meant that they were asked to listen in a relative and not absolute manner. Twenty out of 31 interaction moments for which the answers of at least 9 out of 12 musicians agreed were included for further analysis. The other eleven interaction moments that did not reach this consensus were excluded from further analysis.

\footnotetext{
${ }^{1}$ We want to emphasize that every sound a human voice is expressing, even when produced by a professional singer, always contains a natural fluctuation (Seashore, 1967). In our study this fluctuation often appeared in the form of a very fast glissando, initiating or expanding the salient pitch of an acoustic signal. In using the Melodyne software, we included this salient pitch for analysis (inter-rater reliability of 91.01 (Cohen's $\kappa$ )). However, we often observed slow glissandos that could not be considered a fluctuation around one salient pitch. Unlike Melodyne, which calculates the mean pitch of a whole glissando, we interpreted such a slow glissando as one that consists of two salient pitches: namely, the onset and offset pitches of the glissando (inter-rater reliability of 91.01 (Cohen's $\kappa)$ ).

${ }^{2}$ Each of these programs offers their own merits. The program Cool Edit Pro yields a visual representation of the acoustic signal in a spectrogram obtained by a Fourier analysis. A detailed time-course of frequency is offered by providing precise temporal information regarding the onset and offset times of interaction moments. By this it is possible to define precisely the duration of every tonal interaction moment and the duration of the pauses between them. Melodyne has different capabilities, offering a visual display of the fundamental frequency in an acoustic signal over time and some energy-related information as a calculated mean pitch based on volume-course and duration. The visual display gives a clear view of the pitch at the onset and offset of an acoustic signal and of the most important possible discrete 'pitch-stations' in a continuous course pattern.
} 
Table 2

Estimation of a single population parameter: overview of the observed confidence intervals (95\% significance level) in the harmonic series in percentages.

\begin{tabular}{|c|c|c|c|}
\hline Interval & Mother + infant & Infant & Mother \\
\hline Octave (2:1) & $29.82[27.88 ; 31.76]^{*}$ & 27.39 [23.90; 30.88] & $30.84[28.50 ; 33.17]^{*}$ \\
\hline Fifth $(3: 2)$ & $19.94[18.25 ; 21.64]$ & $24.20[20.85 ; 27.55]$ & $18.17[16.22 ; 20.12]$ \\
\hline Major third (5:4) & $19.01[17.34 ; 20.67]^{*}$ & $19.75[16.63 ; 22.86]^{*}$ & $18.70[16.73 ; 20.67]$ \\
\hline Minor seventh (16:9) & $14.42[12.93 ; 15.91]^{*}$ & $12.26[9.70 ; 14.83]$ & $15.32[13.50 ; 17.14]^{*}$ \\
\hline Major second (9:8) & $10.35[9.05 ; 11.64]^{*}$ & $10.51[8.11 ; 12.91]^{*}$ & $10.28[8.75 ; 11.81]^{*}$ \\
\hline Tritone (45:32) & $2.72[2.03 ; 3.40]$ & $2.87[1.56 ; 4.17]$ & $2.65[1.84 ; 3.46]$ \\
\hline Minor sixth (8:5) & $1.87[1.30 ; 2.45]$ & $1.91[0.84 ; 2.98]$ & $1.86[1.18 ; 2.54]$ \\
\hline Major seventh (15:8) & $1.87[1.30 ; 2.45]$ & $1.11[0.29 ; 1.94]$ & $2.19[1.45 ; 2.93]$ \\
\hline Major triad $(8 \mathrm{th}+5 \mathrm{th}+3 \mathrm{rd})$ & $68.77[66.81 ; 71.72]^{*}$ & $71.34[67.80 ; 76.97]^{*}$ & $67.71[65.35 ; 71.16]^{*}$ \\
\hline Non-major triad (min7th + maj2nd + tritone + min6th + maj7th $)$ & $31.23[29.26 ; 33.21]$ & $28.66[25.13 ; 32.23]$ & $32.29[29.93 ; 34.68]$ \\
\hline
\end{tabular}

"Significant.

\section{Results}

\subsection{Tonal interaction moments (TIM)}

Of the total 558 interaction moments studied, 470 (84.23\%) interaction moments contained clear tonal aspects. We referred to these as 'Tonal Interaction Moments' (TIMs). Within these TIMs, we obtained two categories: (a) TIMs based on the harmonic series (334\% or 71.06\%) (see examples in Fig. 3) or (b) TIMs based on a pentatonic series (136 or $28.94 \%$ ) (see examples in Fig. 4). These TIMS often contained absolute and relative pitch/interval imitations. We will discuss them in more detail below.

\subsection{Other interaction moments}

Of the total 558 interaction moments studied, 88 (15.77\%) interaction moments did not occur in a tonal context based on harmonic or pentatonic series. Fifty-four $(10.31 \%)$ of these interaction moments contained absolute and relative pitch/interval imitations (see examples in Figs. 4-6). The other 34 interactions (6.1\%) did not.

\subsection{Tonal interaction periods (TIP)}

Most of the TIMs appeared on their own as a separate moment, however we observed TIMS that formed a chain with one or more other TIMs. Mother and infant continued in a successive chain of tonalities, and thus possibly used different categories, without making a break in between. It is comparable to a modulation in a piece of music. The music goes on, but along the way the key changes. Sometimes the utterance of the infant was a common tone for both tonalities (see Fig. 6). When a TIM was preceded or succeeded by another TIM with less than $1500 \mathrm{~ms}$ in between, it was counted as one Tonal Interaction Period (TIP). So, a vocalisation pause between two TIPs lasts at least $1500 \mathrm{~ms}$, and one TIP can contain one or more tonalities. This recombination resulted in 361 TIPs.

\subsection{Temporal analysis of the TIPS}

The average duration of the sum of TIPs per dyad (i.e., the average duration that a dyad was in tonal synchrony) during the free-play session ( 4 min $50 \mathrm{~s}$ ) was $89.37 \mathrm{~s}(M=89.37 \mathrm{~s}, \mathrm{SD}=33.93)$. A one-sample Kolmogorov-Smirnov Test showed a normally distributed pattern for the distribution of the total duration of tonal synchrony for a dyad ( $n=15, z=0.468$, $p=0.981$ ).

The average duration of one TIP was $3.71 \mathrm{~s}(M=3.71, \mathrm{SD}=2.44)$ in a range of $0.713-13.257 \mathrm{~s}$. The percentage of the TIPs situated in a range of $1-10$ s was 96.67 (12 outliers).

\subsection{Observed ratios in relation to the tonal centre}

A tonal analysis on the level of the appeared ratios that were used within the harmonic series indicated that both the mother's and the infant's vocalisations were organised around the major triad or the most simple frequency ratios. Together and independently they made significantly more use of major triad tones (e.g., the fundamental frequency, the fifth or the major third) than of non-major-triad tones (mother + infant together: $68.77 \%$; mother independently: 67.71\%; infant independently: 71.34\%) (see Table 2 and Fig. 7).

The distribution of the observed ratios in relation to a tonal centre differed significantly from an equal distribution (mother-infant $\chi^{2}(7, N=2136)=1243.59, p=0.000$; mother $\chi^{2}(7, N=1508)=888.20, p=0.000$; infant $\chi^{2}(7$, $N=628)=376.66, p=0.000$ ). Table 2 shows a strong indication for a hierarchic order in line with the harmonic series observed in these ratios of mother and infant vocalisations. This text only mentions the significant percentages. Mother and infant 
Example 1: Harmonic series G

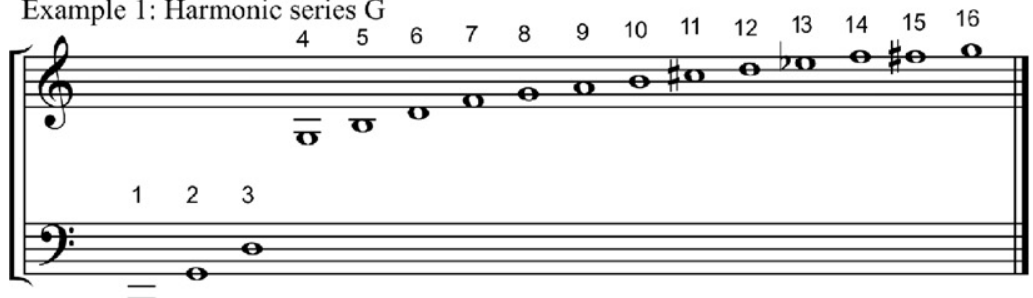

$\overline{\bar{\sigma}}$

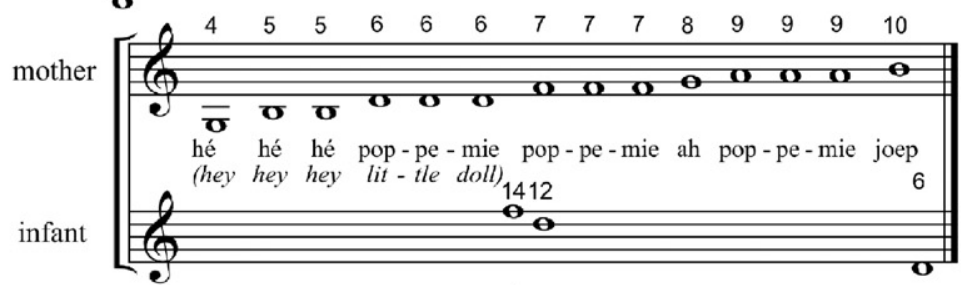

uh

Example 2: Harmonic series A
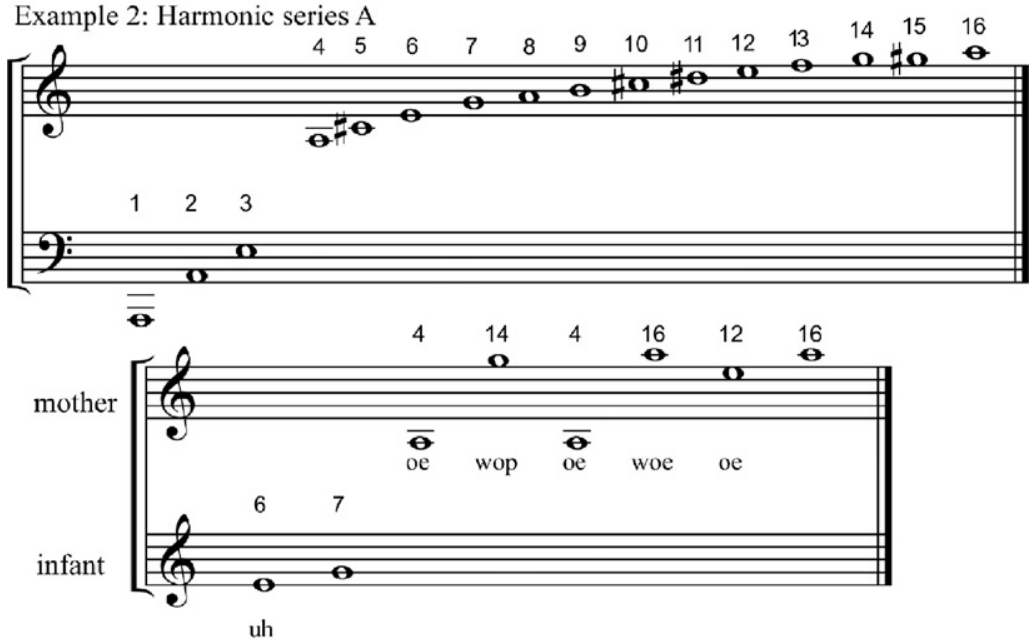

Example 3: Harmonic series B
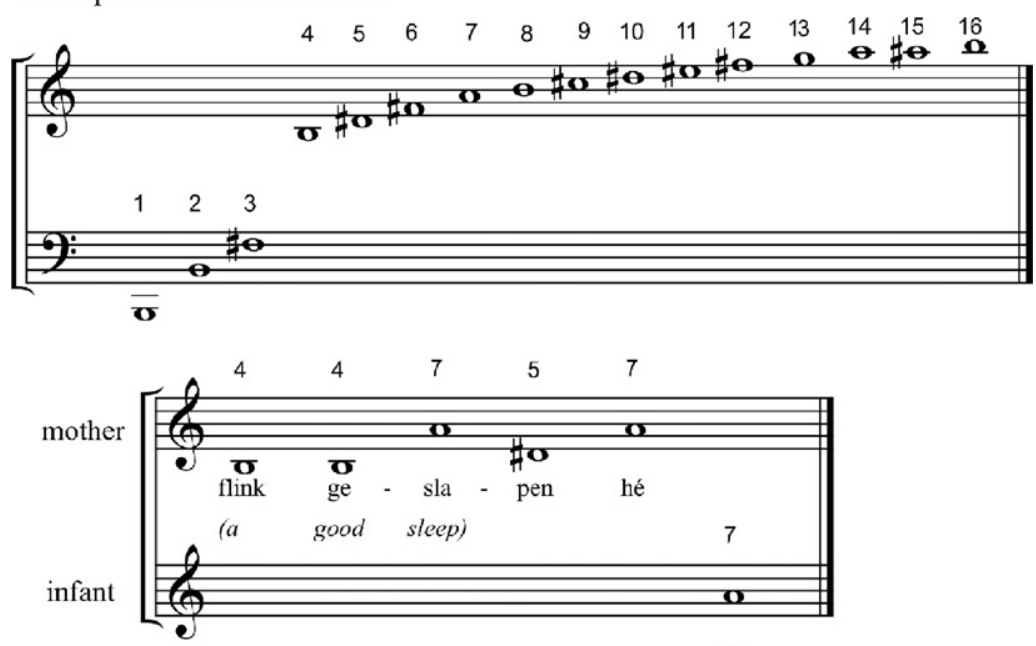

uh

Fig. 3. Three examples of interactions based on a harmonic series. Note: The numbers above the notes in the mother-infant interaction refer to the harmonic number in the harmonic series as explained in Fig. 1. The text between brackets is a free English translation. Example 3 also contained an absolute pitch imitation (more explanation concerning imitations follows in the text below). You can see this in the similar numbers above the notes (number 7 or A-A in example 3). 

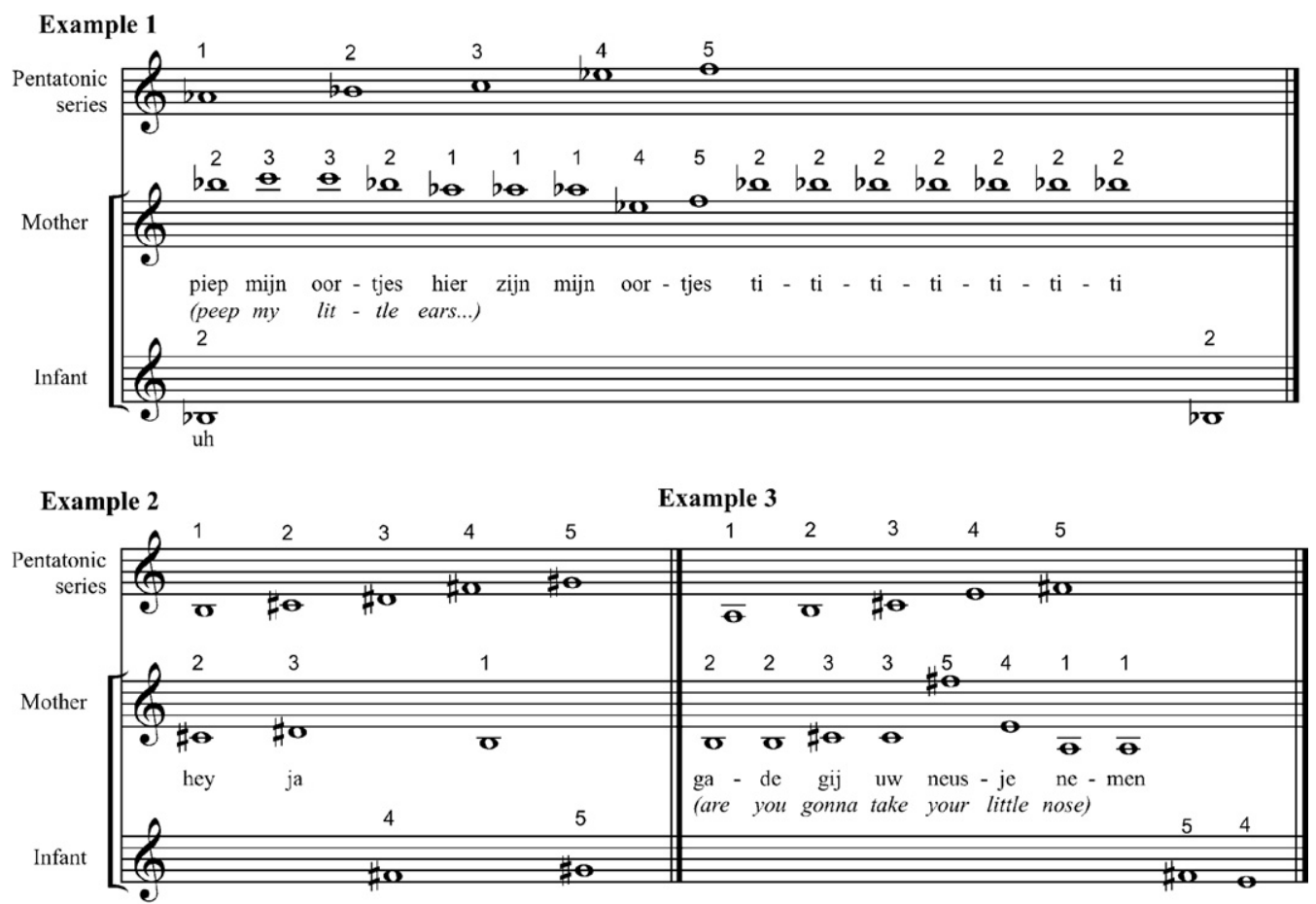

ah

$\mathrm{ah}$

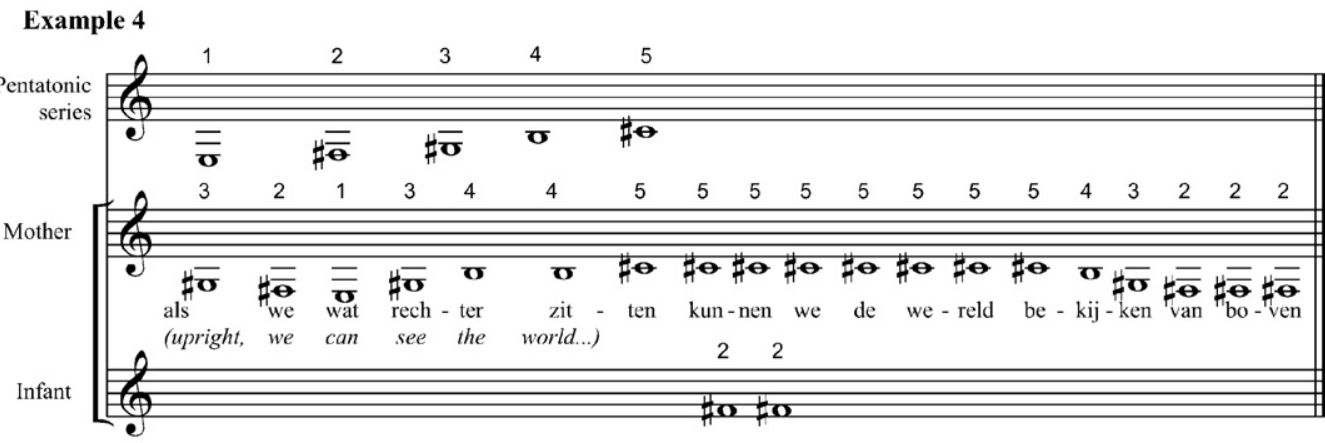

ah

Fig. 4. Four examples of pentatonic interactions. Above each example are the corresponding scale and numbers referring to the corresponding notes. Note: Example 1 also contained two relative pitch imitations (i.e., an octaviation) (more explanation concerning imitations follows in the text below). You can see this in the similar numbers above the notes. The first response of the mother on number 2 or Bb shows an imitation of the infant's utterance on number 2 or Bb two octaves higher and the last response of the infant shows an imitation of its mother's number 2 or Bb two octaves lower.

together made significantly more use of the octave (or tonal centre) than the fifth (637 (29.82\%) octaves against 426 (19.94\%) fifths). As the difference between the fundamental frequency and the fifth was significant for the mother only (465 octaves (30.84\%) against 274 fifths (18.17\%)), this result was defined by the mother's contribution. There was no significant difference between the appearance of the fifth and the major third. Mother and infant together made significantly more use of the major thirds than minor sevenths (406 major thirds (19.01\%) against 308 minor sevenths (14.42\%)), with a significant contribution of the infant (124 major thirds (19.75\%) against 77 minor sevenths (12.26\%)). The minor seventh was significantly more observed than the major second by mother and infant together (308 minor sevenths (14.42\%) against 221 major seconds (10.35\%)), with a significant contribution of the mother (231 minor sevenths (15.32\%) against 155 major seconds $(10.28 \%)$ ). Both mother and infant together and independently made significantly more use of the major second than the tritone (mother + infant together: 221 major seconds (10.35\%) against 58 tritones (2.72\%); mother independently 155 major seconds (10.28\%) against 40 tritones (2.65\%); infant independently 66 major seconds (10.51\%) against 18 tritones (2.87)). The more complex frequency ratios (tritone, minor sixth and major seventh) were used only rarely (see Table $2 \mathrm{a}$ and Fig. 7). 


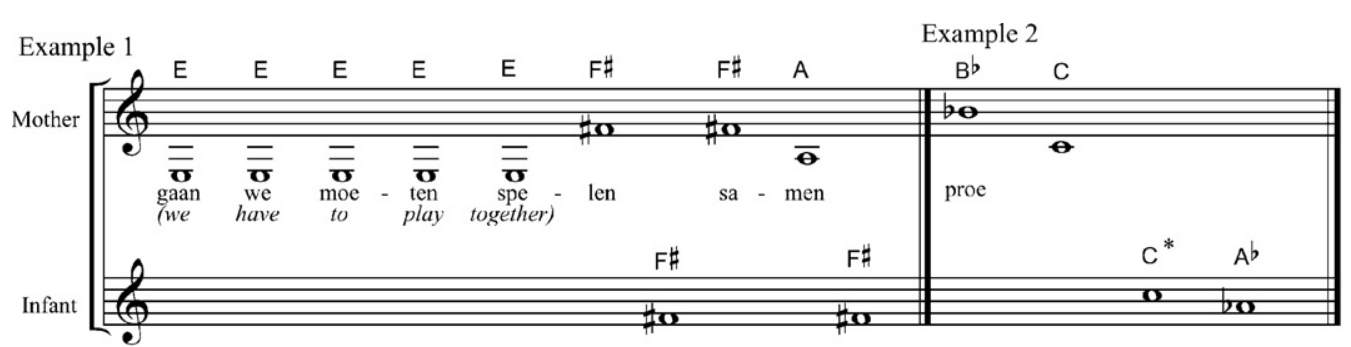

uh

uh

uh

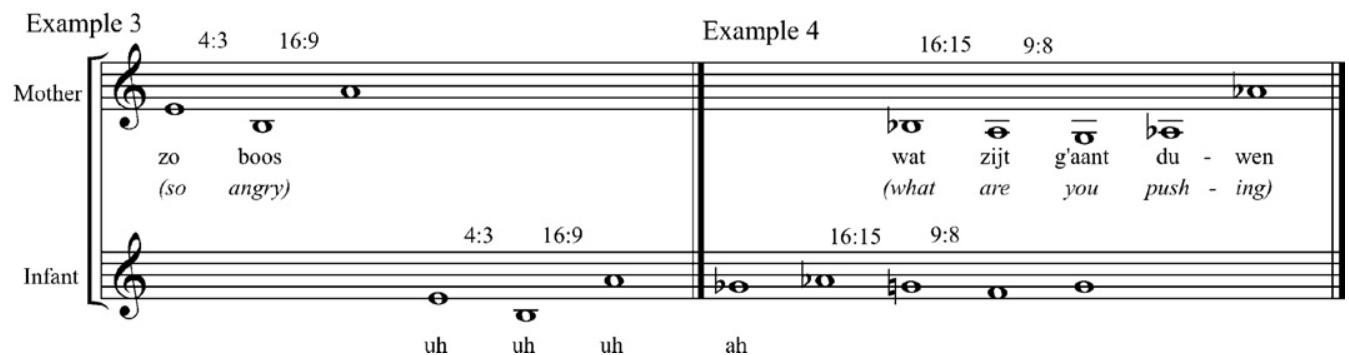

Fig. 5. Four examples of imitations. Note: Example 1 shows two absolute pitch imitations: the infant imitates its mother on F\#. And the mother, on her turn, imitates her infant on F\#. Example 2 contains a relative pitch imitation (i.e., an octaviation). The infant imitates its mother on $\mathrm{C}$ one octave higher $\left(C-C^{*}\right)$. Example 3 shows an absolute interval imitation (ratios 4:3 and 16:9 in the vocalisation of the mother are mirrored by the infant). In example 4 the mother imitates relative tone intervals of the infant (16:15 and 9:8).

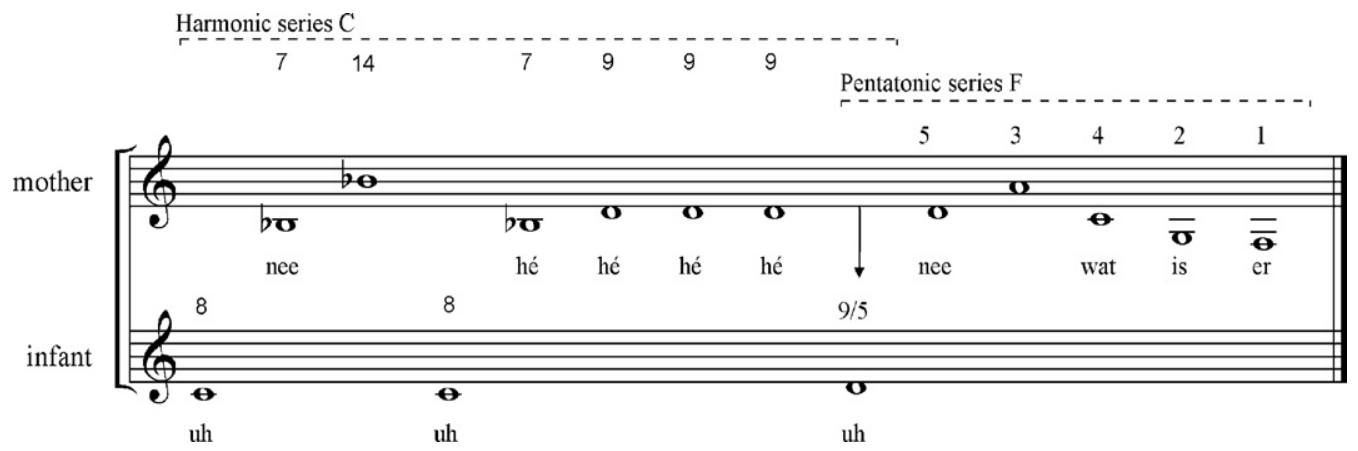

Fig. 6. Example of a TIP consisting out of a TIM based on a harmonic series and a TIM based on a pentatonic series. The arrow points to a utterance of the infant that is part on the one hand of the preceding harmonic series $C$, being harmonic number 9 , and on the other hand of the succeeding pentatonic series $\mathrm{F}$, being the fifth tone. Notice the absolute pitch imitations of mother and infant on a D or harmonic number $9 /$ pentatonic tone 5 .

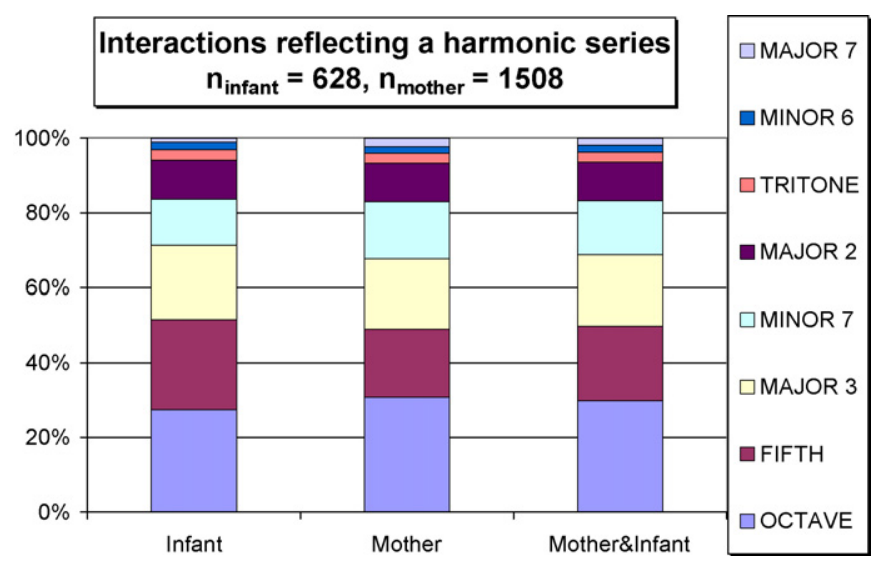

Fig. 7. Overview of all the intervals that appeared during tonal interaction moments within a harmonic series. 


\section{Table 3}

Estimation of a single population parameter: Overview of the observed confidence intervals (95\% significance level) of the intervals in the imitations occurring within a harmonic series in percentages.

\begin{tabular}{|c|c|c|c|}
\hline Interval & Mother + infant & Infant & Mother \\
\hline Octave (2:1) & $33.94[26.71 ; 41.16]$ & $33.63[24.92 ; 42.34]$ & $34.62[21.68 ; 47.55]$ \\
\hline Fifth $(3: 2)$ & $23.64[17.15 ; 30.12]$ & 21.24 [13.70; 28.78] & $28.85[16.53 ; 41.16]$ \\
\hline Major third (5:4) & $16.97[11.24 ; 22.70]$ & $17.70[10.66 ; 24.74]$ & $15.38[5.58 ; 25.19]$ \\
\hline Minor seventh (16:9) & $13.94[8.65 ; 19.22]$ & 13.27 [7.02; 19.53] & $15.38[5.58 ; 25.19]$ \\
\hline Major second (9:8) & $11.52[6.64 ; 16.39]$ & $14.16[7.73 ; 20.59]$ & $5.77[-0.57 ; 12.11]$ \\
\hline Tritone (45:32) & 0.00 & 0.00 & 0.00 \\
\hline Minor sixth (8:5) & 0.00 & 0.00 & 0.00 \\
\hline Major seventh (15:8) & 0.00 & 0.00 & 0.00 \\
\hline Major triad $(8 \mathrm{th}+5 \mathrm{th}+3 \mathrm{rd})$ & $74.55[67.90 ; 85.25]^{*}$ & $72.57[64.34 ; 85.36]^{*}$ & $78.85[67.75 ; 98.36]^{*}$ \\
\hline Non-major triad & $25.45[18.81 ; 31.71]$ & $27.43[19.21 ; 35.30]$ & $21.15[10.05 ; 31.26]$ \\
\hline
\end{tabular}

"Significant.

\subsection{Imitations}

Infants matched their mother's pitch either in absolute or in relative terms two times more than mothers matched their infant's pitch (99 absolute pitch matches of the infant against 44 absolute pitch matches of the mother; 96 relative pitch matches of the infant against 52 relative pitch matches of the mother). Mothers and infants also imitated frequency ratios or intervals in one another's successive vocalisations either in absolute (i.e., an identical interval is repeated on the same pitch) or relative terms (i.e., an identical interval is repeated starting from a different tone). Thirteen interval imitations by the infant ( 6 absolute and 7 relative interval imitations) and 17 interval imitations by the mother ( 3 absolute and 14 relative interval imitations) were observed.

When imitations took place in a harmonic series, the tones of the major triad were favoured by both mother and infant. Mother and infant made together and independently significantly more use of major triad tones than of non-major-triad tones in their imitations. In 74\%, 55\% of the cases mother and infant together imitated each other by using tones of the major triad (165 tones) (infant independently: 72.57\%(113 tones) and mother independently: $78.85 \%$ (52 tones)). The tritone, minor sixth and major seventh were never imitated: not by mothers, nor by infants. There are indications that the appearance of the imitations reflects the hierarchy of the harmonic series, however these trends were not significant at the required 95\% level (see Table 3 and Fig. 8).

\subsection{Tritone analysis}

TIPs that contained one ore more tritones could be categorised in three situation-conditions: (a) 'neutral condition' (37.21\%), where the tritone did not fulfil any specific function; (b) 'attention' (34.88\%), indicating TIPs during which the mother was trying to catch the attention of the infant; and (c) 'discontentment' (27.91\%), where the mother was reacting to a state of discontentment of the infant (e.g., being hungry, not sitting comfortably, getting tired ...) (see Fig. 9).

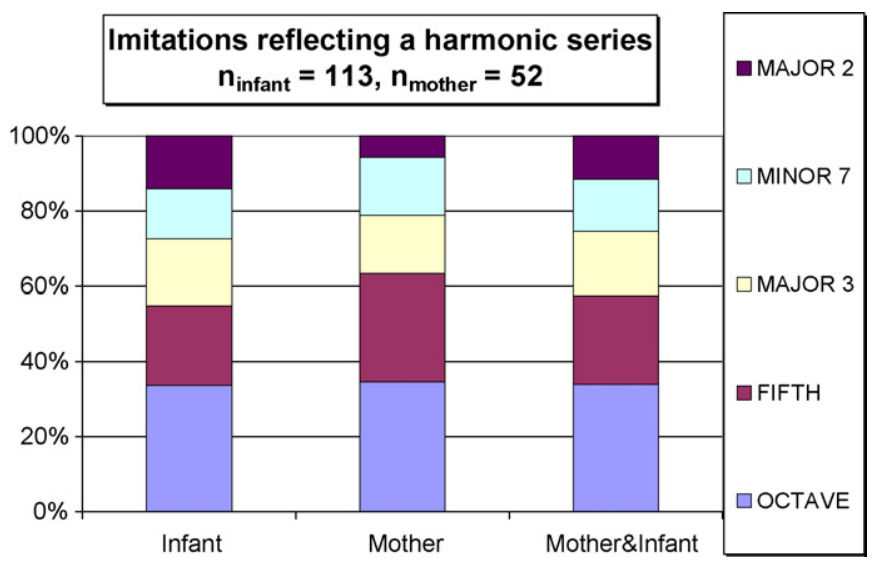

Fig. 8. Overview of the intervals that appeared during imitations that took place within a harmonic series. Note. Notice the large part played by major triad tones. 


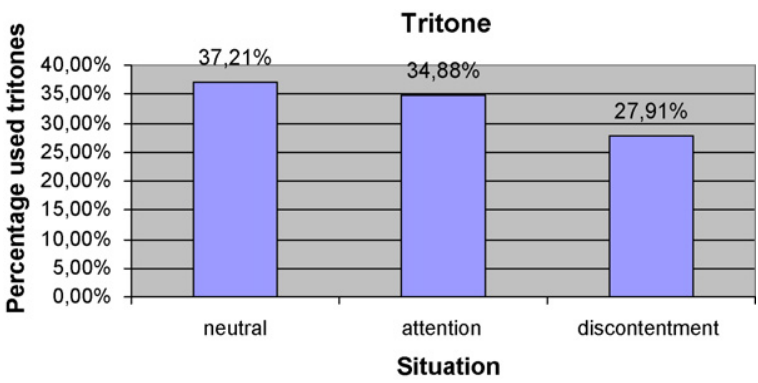

Fig. 9. The percentages of the observed tritones within three different situations.

\section{Discussion}

Starting with the different features that have to be assigned to ID speech, we presented a detailed tonal analysis that revealed a new concept that has not yet been described in the literature: "Tonal synchrony". Tonal synchrony covers a vertical tonal analysis combined with a horizontal temporal analysis. During a tonal interaction period (TIP) a mother and infant exchange vocalisations based on tonal aspects. Tonality has a different meaning than music, as the word 'music', to us, inevitably implies a cultural influence. Tonality, in its own way, can be considered as an underlying basic level that contains universal nature-based aspects, such as the harmonic series with its simple frequency ratios from which cross-cultural musical systems can be derived (Meyer, 1956). During vocal exchanges between mother and infant, these tonal aspects appear in a temporal-based pattern that contains basic aspects of synchrony such as simultaneous vocalising and successive turn-taking.

Almost $85 \%$ of the 558 interaction moments studied in our observations contained one or more tonal aspects in terms of harmonic series, simple frequency ratios and pentatonic series, often intertwined by a mirroring pattern of pitch and/or interval imitations. Concerning the claim of Bergeson and Trehub (2007) that "the component intervals of maternal tunes had little resemblance to conventional music intervals or to the structure of musical sequences, which makes it unlikely that music is the source of tunes in IDS" (pp. 652-653), and the conclusion of Eckerdal and Merker (2008): “... none of the infant capacities and behaviors we have dealt with are in any way specifically related to music", we stress - based on our findings - that ID speech can be linked to music in a specific way. ID speech and music seem to share the same universal source, namely harmonics. More than $70 \%$ of the TIMs reflected a harmonic series. Interestingly, when mother and infant vocalised within a harmonic series, their vocalisations were principally organised around the major triad. Within this major triad, the tonal centre was omnipresent. The hierarchy of the harmonic series and the ubiquity of the simple frequency ratios are possibly so prevalent in human life that even an infant seems to incorporate it. These preferences can possibly be connected to research showing that infants perceive changes more readily within the major triad than within, for example, an augmented triad (Trainor \& Trehub, 1993). Also in line with the hierarchic structure of the harmonic series, the next most used harmonic was the minor seventh. The major seventh however was observed very rarely, possibly as a result of the preference for simple frequency ratios over complex frequency ratios. Although the minor seventh also forms a complex frequency with reference to the fundamental frequency, it possesses a much less tense relationship, as it is located a whole tone or major second (ratio 9:8) below the octaviated fundamental frequency, whereas the major seventh is positioned a semitone or minor second (ratio 16:15) below the octaviated fundamental frequency. Semitones are experienced as dissonant and we suspect that for this reason they are less used in a tonal communication framework. This supposition is supported by the clear presence of the major second (harmonic number 9) in the vocalisations. Strikingly, in jazz and blues, the term 'bluenote' denotes the frequent construction where the minor seventh is placed upon the major triad. So indeed, ID speech resembles jazz music not only rhythmically (Gratier, 2000; Schögler, 1998), but also tonally. Within the interactions, the tritone was sometimes used. Knowing that the tritone is the most complex frequency ratio $(11: 8)$, thus more complex than for example the major seventh, and experienced as extremely dissonant, we suspect its salient property might fulfil an attention-regulating or discontentment-communicating function.

A second category - pentatonic series - accounted for almost $25 \%$ of the TIMs. As an anhemitonic pentatonic scale is built out of ascending simple frequency ratios 3:2, we consider this cross-cultural deduction as a universal tonal aspect. It is important to understand that the harmonic and pentatonic series have the major triad and the major second in common. The difference between both, however, can be found in the major sixth in relation to the fundamental frequency. The major sixth forms part of the pentatonic series, being the fifth note (see for example in Fig. 2: D or tone number 5) but is not found in the harmonic series. Conversely, the minor seventh belongs to the harmonic series and does not appear in the pentatonic series. Moreover, they do relate to each other as a semitone. This is possibly why we never found the major sixth and the minor seventh within the same TIM.

Another interesting interval is the fourth with reference to the fundamental frequency, which neither belongs to the pentatonic series (however the interval is a simple frequency ratio in relation to the third harmonic), nor to the harmonic series. It was never used within the TIMs or TIPs. Had one used the fourth in relation to the fundamental frequency, it would 
not only have introduced a note that does not belong to one of the series, but it would also have altered the harmonic series and with it, the tonality. A fourth interval always moves toward the fundamental frequency, as one can see between the harmonic numbers 3 and 4, but never away from the fundamental frequency. A fourth upward on a fundamental frequency transforms the fundamental frequency to the fifth of a new harmonic series of which the fourth becomes the fundamental frequency. To conclude, mother and infant appear to prefer tonality above simple frequency ratios.

Pitch-matching has been described in a few studies of young infants from 0 to 6 months (Gratier, 2003; Kessen, Levine, \& Wendrich, 1979). However, other research studying infants between 8 and 12 months reported against pitch-matching (Siegel, Cooper, Morgan, \& Brenneise-Sarshad, 1990). One study described adults that adjusted to their infant's pitch but not the other way round. In this study we observed 291 pitch imitations and 30 interval imitations. Moreover, an infant matched his mother's pitch twice as much as a mother matched her infant's pitch. Ninety percent of these imitations occurred within a harmonic or pentatonic series. And in almost $75 \%$ of the cases within a harmonic series, the tones of the major triad were favoured by both mother and infant - almost as if they wished to confirm their co-created tonality to one another. In contrast, the minor sixth, the tritone and the major seventh were never imitated. Possibly, a tonal context of simple frequency ratios triggers more imitations by an infant, and thus more infant-mother interactions, than a context of more complex frequency ratios. We wonder if the absolute pitch imitations are a form of reflexive mirroring exchanges comparable to those in facial and gestural modalities (Meltzoff \& Moore, 1994; Stern, 2002) that serve as a way of attuning to each other's psychophysiological state.

The rich presence of tonal aspects in an early mother infant dyad could be considered an ontogenetic mirroring of Darwin's phylogenetic suggestion (1872/1965) that "the progenitors of man probably uttered musical tones before they had acquired the power of articulated speech ... when the voice is used under any strong emotion it tends to assume a musical character" (p. 86). As such, we would like to claim that, in contrast to Pinker (1997) - for whom any form of music has no functional advantages and who disconnects an innate linguistics from acquired musical components - tonal aspects possibly accomplish a function primary to linguistics to provide us with emotional intuitive-based information.

The temporal analysis showed a normally distributed pattern of the total duration of tonal synchrony for a dyad. Further research could shed light on the exact meaning of this pattern. Earlier research from Beebe et al. (2001) regarding vocal rhythm coordination revealed a relation between a mid-range vocal rhythm matching and secure attachment, whereas both low and high vocal rhythm matching were related to an insecure attachment. The possibility of analogous relations between tonal synchrony and developmental aspects such as bonding, attachment and emotional availability must be investigated.

It has already been described how a mother responds to an infant's capacity to detect contingence between discrete events in the behaviors of the dyad and its environment (Feldman, 2007). Until now this description has been limited to temporalbased aspects. Tonal synchrony however, adds a contingent aspect based on the hierarchical order of the harmonic series that might supply the mother-infant attunement with an extra intuitive stream of information on the intersecting planes of time and emotion. The difference between tonality and atonality has everything to do with stabilising and destabilising an atmosphere. This means that tonality can exchange messages that embody signals of tension or relaxation on a pre-reflective level. We observed a likewise time-course through which mother and infant alternately 'tune in and out' into one another in alternating tonal and non-tonal interaction moments and/or periods. The average duration of one TIP counts $3.71 \mathrm{~s}$ with a range of about $1-10 \mathrm{~s}$ (12 outliers). These timing aspects are related remarkably well with the temporal architecture of Stern's (2004) concept of "the present moment" that has been connected to aspects of "communicative musicality" in a mother-infant relationship (Malloch \& Trevarthen, 2008). Stern (2004) referred to the present moment as a moment of primary subjective reality or subjective experience as it is occurring. He described it as a subjective, psychological, process unit of which one is aware (p. 25). During a present moment the flow of perceptual stimulation is unconsciously chunked into meaningful units leading to a rise of awareness and consciousness. The present moment as a basic process unit of a global experience occurring in a subjective now has a duration comparable to the time parameters in music, poetry, dance, gesture, kinetics, and discourse. But seemingly it is also comparable to the duration of TIPs as described in this study. TIPs seem to refer to Stern's present moments of intersubjective creation in which the lived experience happens between two (or more) people as a shared experience that becomes part of the implicit knowledge of their relationship. The findings of the study are suggestive of a confirmation that communicative musicality, more specifically in its form of tonal interaction synchrony, is a major route to create early forms of present moments of intersubjectivity.

An important remark on this study is the fact that we made a comparison between a natural-based frequency scheme of the harmonic series and the frequencies related to the note-names of an equal-tempered system. The most important deviations are (see Table 1 ) minor seventh ( -31.2 cents), tritone ( -9.8 cents), minor sixth ( +13.7 cents), major third ( -13.7 cents) and major seventh ( -11.7 cents). This means that the two most common intervals in this study (almost $50 \%)-$ the octave and the fifth - display no, or very little, deviation. However, the major third and minor seventh also played an important part in the vocal exchanges (33\%). When the 12 musicians did not obtain a consensus, post-interviews showed that this was often the consequence of a hesitation in differentiating between either a minor third and major third or a sixth and minor seventh. Further research must reveal if a mother-infant dyad instinctively approximate the natural ratios of the harmonic series instead of the equal-tempered ones.

We believe this study may open new pathways for empirical research and may possibly have clinical applications. Is tonal synchrony specific to a dyad in the bonding phase to disappear at later ages, or is it a relational quality that continues throughout a child's development? Does tonal synchrony appear in the same form in other cultures? Further research could take up this questions to reveal its occurrence in other cultures, and its impact on a child's development. 


\section{Acknowledgment}

The research reported here was supported by grant HOA8 from the Research Counsel of the Vrije Universiteit Brussel.

\section{References}

Beebe, B., Feldstein, S., Crown, C. L., \& Jasnow, M. D. (2001). Rhythms of dialogue in infancy: Coordinated timing and infant development. Society for Research in Child Developmental Monograph Series.

Bergeson, T. R., \& Trehub, S. E. (2007). Signature tunes in mothers' speech to infants. Infant Behavior and Development, 30(4), 648-654.

Blood, A. J., Zattore, R. J., Bermudez, P., \& Evans, A. C. (1999). Emotional responses to pleasant and unpleasant music correlate with activity in paralimbic brain regions. Nature Neuroscience, 2(4), 382-387.

Burns, E. M., \& Dixon, W. W. (1982). Intervals, scales, and tuning. In D. Deutsch (Ed.), The psychology of music (pp. 241-269). New York: Academic Press Inc. Cooper, R. P., \& Aslin, R. N. (1990). Preference for infant-directed speech in the 1st month after birth. Child Development, 61(5), $1584-1595$.

Darwin, C. (1965). The expression of the emotions in man and animals. Chicago/London: The University of Chicago Press. (original work published 1872).

Demany, L., \& Armand, F. (1984). The perceptual reality of tone chroma in early infancy. Journal of the Acoustical Society of America, 76, 57-66.

Dowling, W. J., \& Harwood, D. L. (1986). Music cognition. San Diego: Academic Press.

Eckerdal, P., \& Merker, B. (2008). 'Music' and the 'action song' in infant development: An interpretation. In S. Malloch, \& C. Trevarthen (Eds.), Communicative musicality (pp. 241-262). Oxford: University Press.

Feldman, R. (2007). Parent-infant synchrony and the construction of shared timing; Physiological precursors, developmental outcomes, and risk conditions. Journal of Child Psychology and Psychiatry, 48(3/4), 329-354.

Fernald, A. (1985). Four-month-old infants prefer to listen to motherese. Infant Behavior and Development, 8, 181-195.

Fernald, A. (1989). Intonation and communicative interest in mother's speech to infants: Is the melody the message? Child Development, 60, $1497-1510$.

Fernald, A. (1992). Meaningful melodies in mothers' speech to infants. In H. Papousek, U. Jürgens, \& M. Papousek (Eds.), Nonverbal vocal communication: Comparative and developmental approaches (pp. 262-282). Cambridge: Cambridge University Press.

Fernald, A. (1993). Approval and Disapproval: Infant responsiveness to vocal affect in familiar and unfamiliar languages. Child Development, 64, 657-667.

Fernald, A., \& Simon, T. (1984). Expanded intonation contours in mothers' speech to newborns. Developmental Psychology, 20(1), $104-113$.

Fernald, A., Taeschner, T., Dunn, J., Papousek, M., de Boisson-Bardies, B., \& Fukui, I. (1989). A cross-language study of prosodic modifications in mothers' and fathers' speech to preverbal infants. Journal of Child Development, 16, 477-501.

Gratier, M. (2000). Accordages et Contretemps: Harmonies entre mère et bébé. Enfance \& Psy, 13, 9-15.

Gratier, M. (2003). Expressive timing and interactional synchrony between mothers and infants: Cultural similarities, cultural differences, and the immigration experience. Cognitive Development, 18(4), 533-554.

Grieser, D. L., \& Kuhl, P. K. (1988). Maternal speech to infants in a tonal language. Support for universal prosodic features in motherese. Developmental Psychology, 24(1), 14-20.

Helmholtz, H. (1954). On the sensations of tone as a physiological basis for the theory of music. New York: Dover Publications. (original work published 1863).

Jaffe, J., Beebe, B., Feldstein, S., Crown, C. L., \& Jasnow, M. D. (2001). Rhythms of dialogue in infancy. Monographs of the Society for Research in Child Development (2, serial no. 265).

Jiang, X., Geerinck, T., Patsis, G., Kog, M., Loots, G., Verhelst, W., et al. (2007). Audiovisual scene analysis: Mother-child communication. In Proceedings of the XIII-th Convention of Electrical Engineering, CIE 2007 Santa Clara, Cuba, June 18-22.

Kennedy, M. (1994). The Oxford dictionary of music (2nd ed.). Oxford: Oxford University Press.

Kessen, W., Levine, J., \& Wendrich, K. A. (1979). The imitation of pitch in infants. Infant Behavior and Development, 2, 93-100.

Kisilevsky, B. S., Hains, S. M. J., Brown, C. A., Lee, C. T., Cowperthwaite, B., Stutzman, S. S., et al. (2009). Fetal sensitivity to properties of maternal speech and language. Infant Behavior and Development, 32, 59-71.

Kisilevsky, B. S., Hains, S. M. J., Lee, K., Xie, X., Huang, H., Ye, H.-H., et al. (2003). Effects of experience on fetal voice recognition. Psychological Science, 14, 220-224.

Koelsch, S., Fritz, T., V Cramon, Y. D., Müller, K., \& Friederici, A. D. (2006). Investigating emotion with music: An fMRI study. Human Brain Mapping, 27, 239-250.

Lecanuet, J.-P. (1996). Prenatal auditory experiences. In I. Deliège, \& J. Sloboda (Eds.), Musical beginnings: Origins and development of musical competence (pp. 37-54). Oxford: Oxford University Press.

Malloch, S. N. (1999-2000). Mothers and infants and communicative musicality (Special Issue). Musicae Scientiae: Rhythm, Musical Narrative and Origins of Human Communication, 29-57.

Malloch, S., \& Trevarthen, C. (2008). Communicative musicality. Exploring the basis of human companionship. Oxford: University Press.

Marler, P. (1990). Innate learning preferences: Signals for communication. Developmental Psychobiology, 23(7), 557-568.

Meltzoff, A. N., \& Moore, M. K. (1994). Imitation, memory, and the representation of persons. Infant Behavior and Development, 17(1), 83-100.

Meyer, L. B. (1956). Emotion and meaning in music. Chicago: The University of Chicago Press.

Miall, D. S., \& Dissanayake, E. (2002). The poetics of babytalk. Human Nature, 14, 337-364.

Narmour, E., \& Solie, R. A. (Eds.). (1988). Explorations in music, the arts, and ideas. Essays in honor of Leonard B. Meyer. Stuyvesant: Pendragon Press.

Papousek, M. (1992). Early ontogeny of vocal communication in parent-infant interactions. In H. Papousek, U. Jürgens, \& M. Papousek (Eds.), Nonverbal vocal communication: Comparative and developmental approaches (pp. 230-261). Cambridge: Cambridge University Press.

Papousek, H. (1996). Musicality in infancy research: Biological and cultural origins of early musicality. In I. Deliège, \& J. Sloboda (Eds.), Musical beginnings: Origins and development of musical competence (pp. 37-54). Oxford: Oxford University Press.

Papousek, M. (1996). Intuitive parenting: A hidden source of musical stimulation in infancy. In I. Deliège, \& J. Sloboda (Eds.), Musical beginnings: Origins and development of musical competence (pp. 88-112). Oxford: Oxford University Press.

Pinker, S. (1997). How the mind works. New York: Norton.

Sadie, S. (Ed.). (1980). The new Grove's dictionary of music and musicians. London: Macmillan.

Schellenberg, E. G., \& Trehub, S. E. (1994). Frequency ratios and the perception of tone patterns. Psychonomic Bulletin E Review, 1, $191-201$.

Schellenberg, E. G., \& Trehub, S. E. (1996a). Children's discrimination of melodic intervals. Developmental Psychology, 32(6), 1039-1050.

Schellenberg, E. G., \& Trehub, S. E. (1996b). Natural musical intervals: Evidence from infant listeners. Psychological Science, 7(5), $272-277$.

Schögler, B. (1998). Music as a tool in communications research. Nordic Journal of Music Therapy, 7(1), 40-49.

Seashore, C. E. (1967). Psychology of music. New York: Dover Publications.

Siegel, G. M., Cooper, M., Morgan, J. L., \& Brenneise-Sarshad, R. (1990). Imitation of intonation by infants. Journal of Speech and Hearing Research, 33, 9-15.

Stern, D. N. (2002). The first relationship: infant and mother. Cambridge: Harvard University Press.

Stern, D. N. (2004). The present moment in psychotherapy and everyday life. New York: Norton \& Company.

Stern, D. N., Spieker, S., \& MacKain, K. (1982). Intonation contours as signals in maternal speech to prelinguistic infants. Developmental Psychology, 18, 727-735.

Trainor, L. J., Austin, C. M., \& Desjardins, R. N. (2000). Is infant-directed speech prosody a result of the vocal expression of emotion? Psychological Science, 11(3), 188-195.

Trainor, L. J., \& Trehub, S. E. (1993). What mediates infants' and adults' superior processing of the major over the augmented triad? Music Perception, 11(2), $185-196$. 
Trehub, S. E. (2001). Musical predispositions in infancy. Biological Foundations of Music Annals of the New York Academy of Sciences-Paper Edition, 930, 1-16. Trevarthen, C. (1999/2000). Musicality and the intrinsic motive pulse: Evidence from human psychobiology and infant communication (Special Issue). Musicae Scientiae: Rhythm, Musical Narrative and Origins of Human Communication, 157-213.

van der Meulen, B. F., Ruiter, S. A. J., lutje Spelberg, H. C., \& Smrkovsky, M. (2000). BSID-II-NL: Bayley scales of infant development (2nd ed.). Harcourt. (Dutch version).

Werker, J. F., Pegg, J. E., \& McLeod, P. J. (1994). A cross-language investigation of infant preference for infant-directed communication. Infant Behavior E Development, 17(3), 323-333.

Zentner, M. R., \& Kagan, J. (1998). Infants' perception of consonance and dissonance in music. Infant Behavior \& Development, 21(3), 483-492.

Zink, I., \& Lejaegere, M. (2002). N-CDIs: Lijsten voor Communicatieve Ontwikkeling. Aanpassing en hernormering van de MacArthur CDIs van Fenson et al. (Lists for communicative development). Leuven/Leusden, Belgium: Acco. 